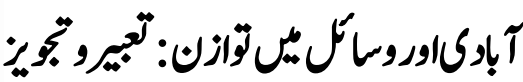

\section{Equilibrium of Population and Resources: Interpretation and Approach}

Muhammad Aminuddin ${ }^{*}$

Bilal Hussain**

Pirzada Junaid Amin ${ }^{* * *}$

\begin{abstract}
Population and resources have an interdisciplinary relationship. The establishment of a sustainable society depends upon a balanced family. Environment, health, and socio-economic peace and prosperity are tempered due to rapid variations. The population and resources gap is misinterpreted in particularly in Muslim societies. The population has been recognized symbol of power for a country. Shortage of resources is not caused by population growth but a result of mismanagement. This crisis requires contemporary interpretation and some indirect approaches. Islam is a balanced religion and encourages balanced life and society. The article in hand will review the policies taken by various Muslim countries. It will denote governmental campaigns for management of family and resources. This paper will provide Islamic instructions on the equilibrium of population and resources. It will discuss minutely legitimacy of the population equilibrium campaign. This research will highlight the approachable zones to address this burning issue. It will introduce swift actions to be taken by individuals and the community at large.
\end{abstract}

Keywords: Population, Resources, Family, Islam, Approach

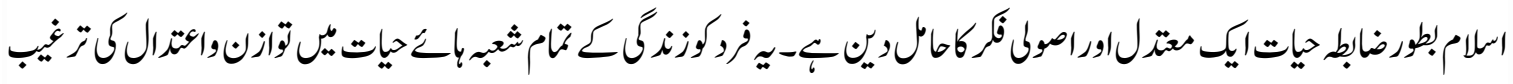

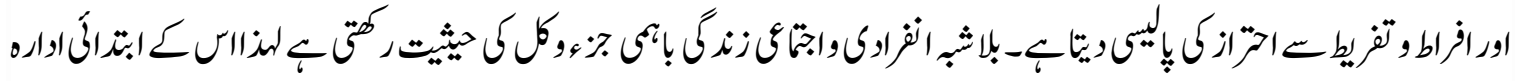

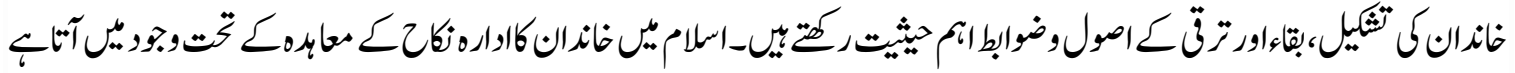

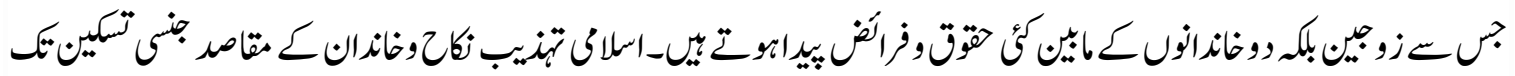

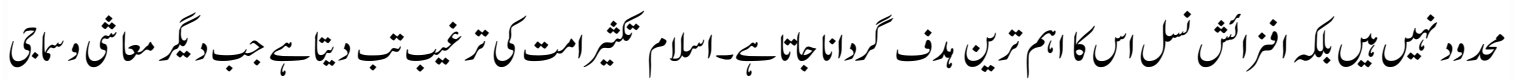

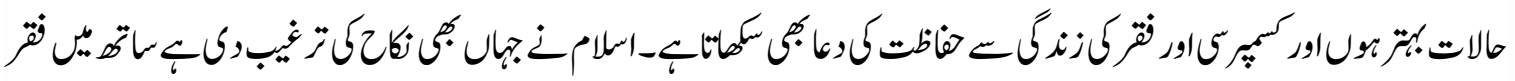

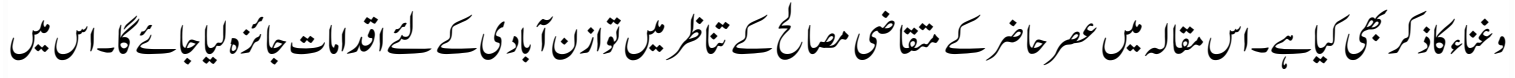

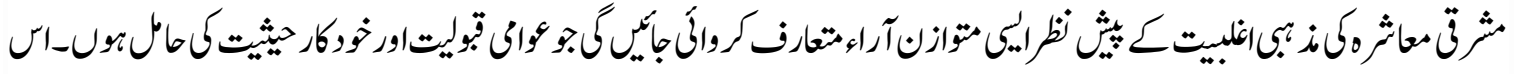

* Lecturer, Department of Islamic Studies, Bahria College, Islamabad

${ }^{* *}$ Research Investigator Law, Department of Law, Council of Islamic Ideology, Islamabad.

Email: dlaw@cii.gov.pk, hmbilal1204@gmail.com

${ }^{* * *}$ Member of Council of Islamic Ideology, Islamabad. 


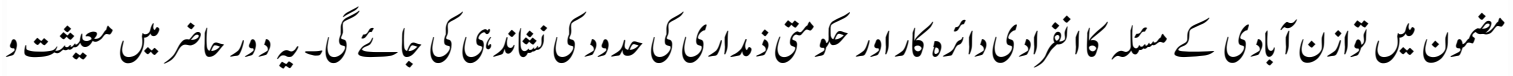

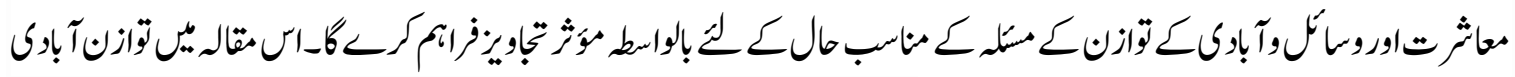

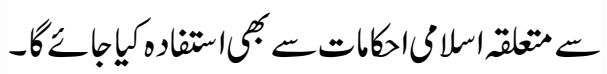

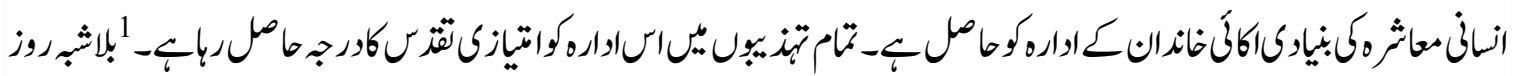

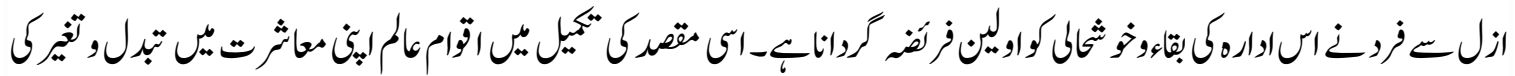

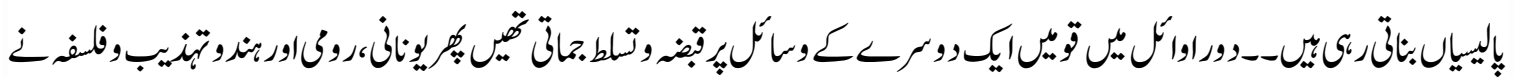

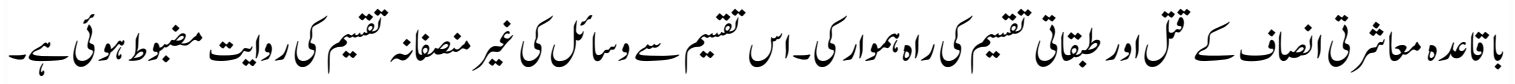

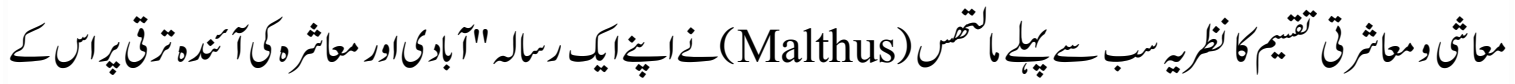

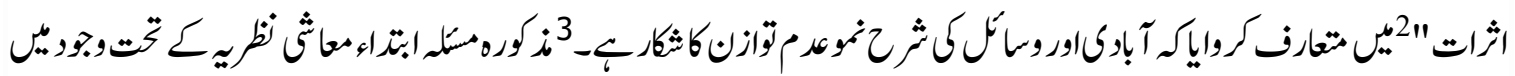

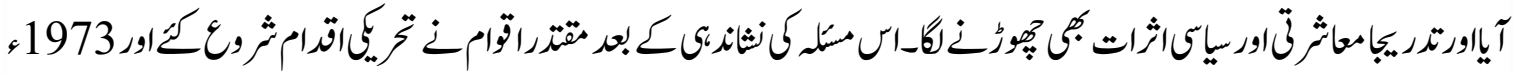

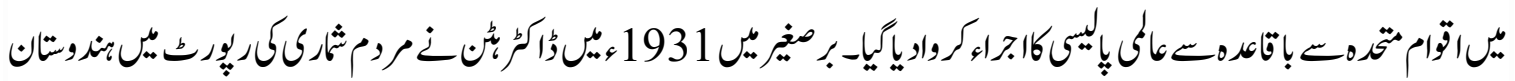

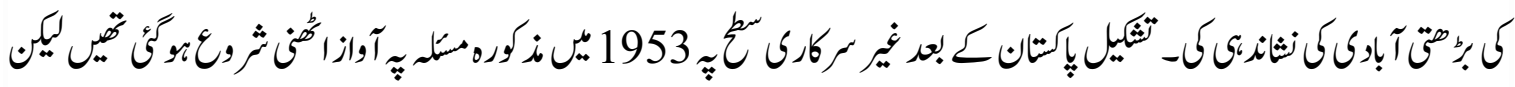

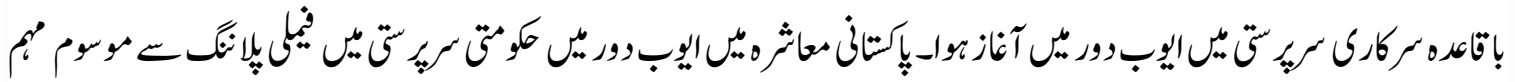

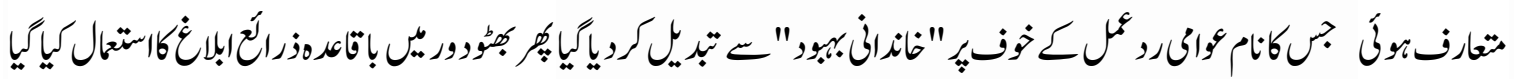

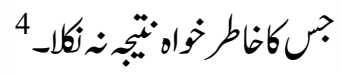

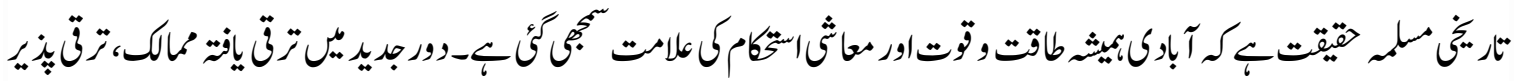

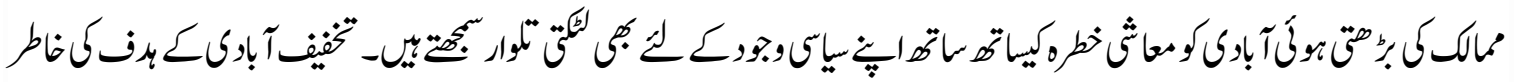

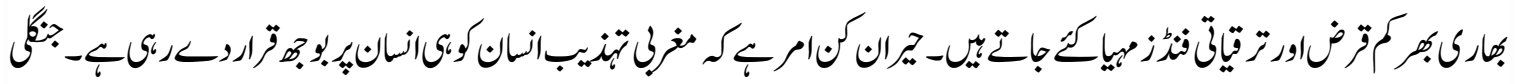

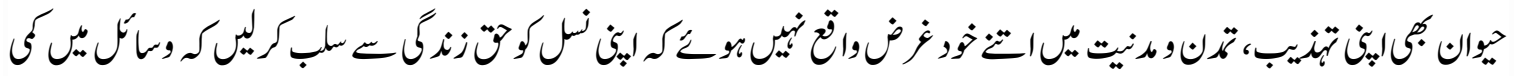

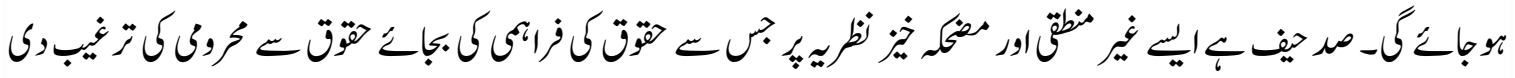

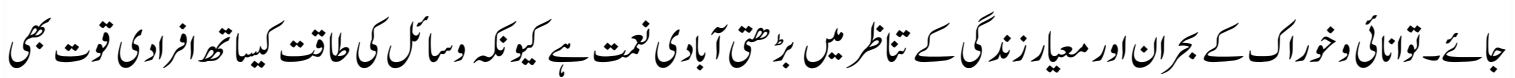

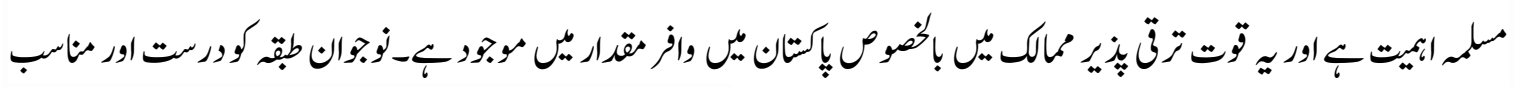

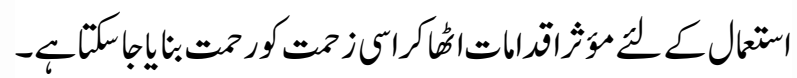

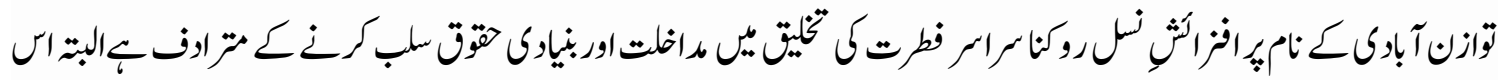




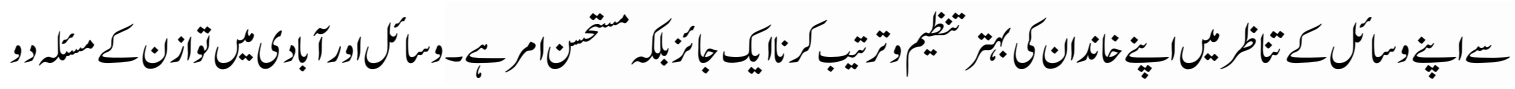

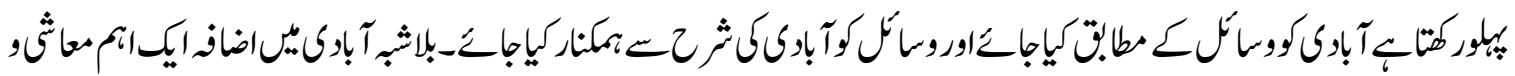

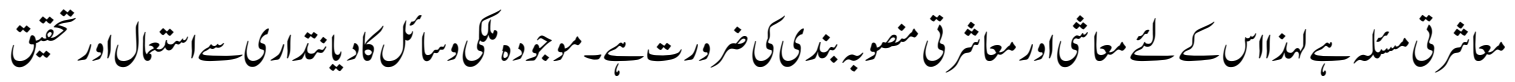

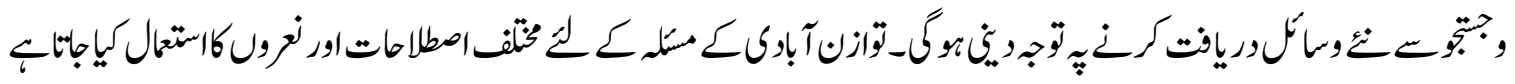

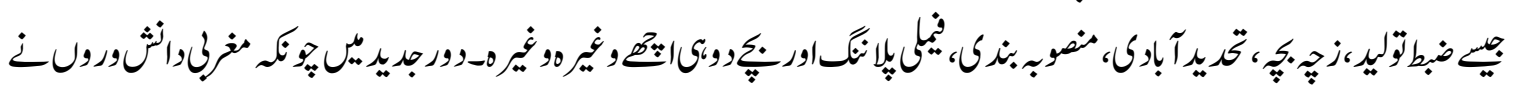

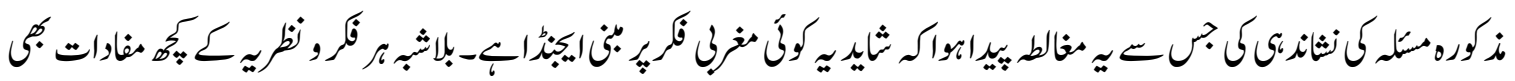

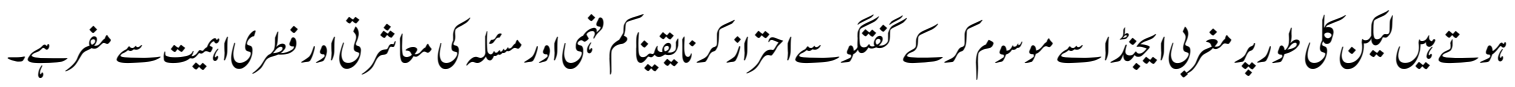

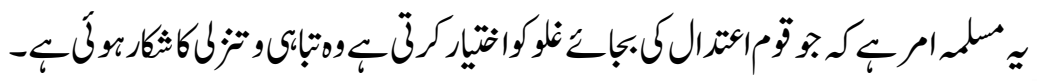

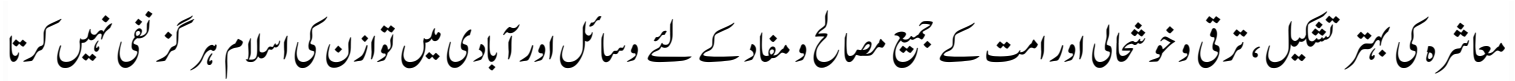

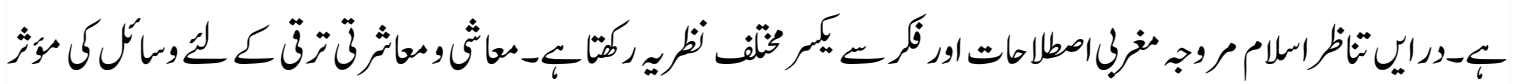

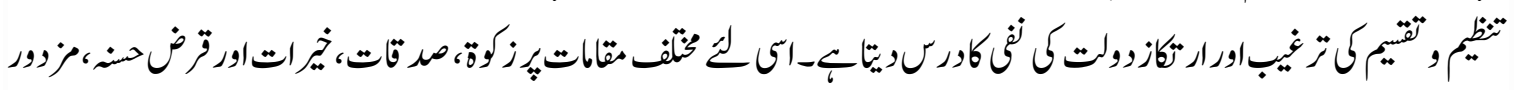

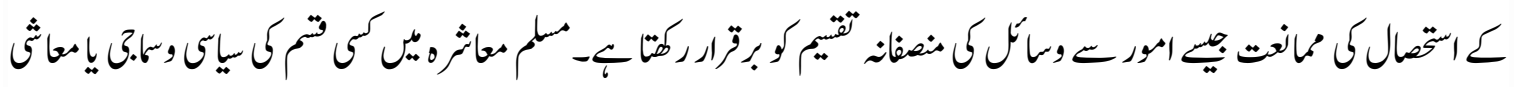

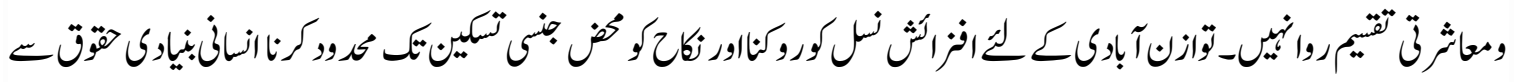

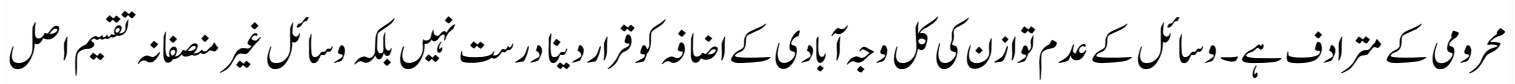

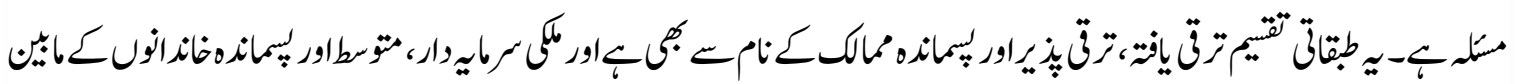

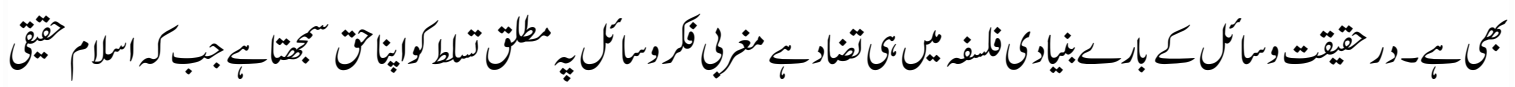

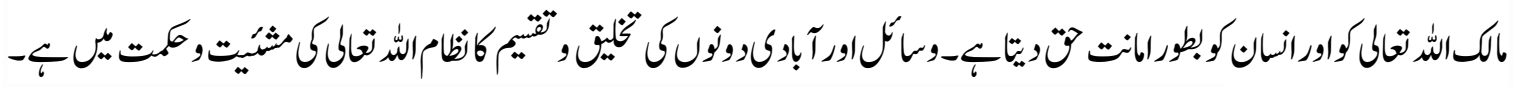

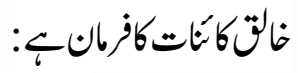
"وما من دابة في الأرض إلا على الله رزقها ويعلم مستقرها ومستودعها كل في كتاب مبين"5

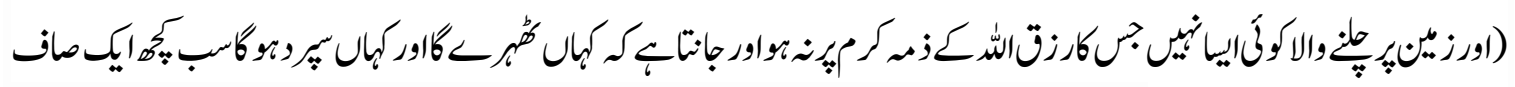

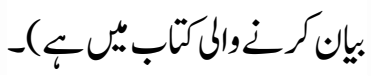

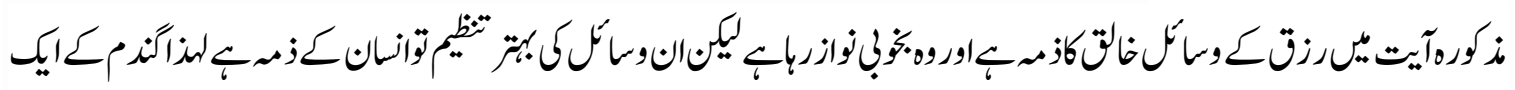

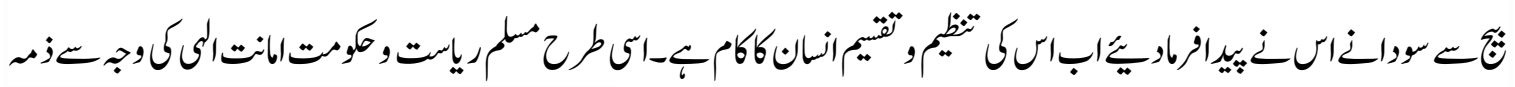

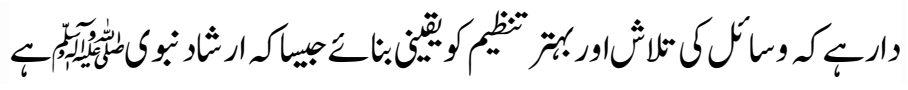


"فالإمام الذي على الناس راع وهو مسئول عن رعيته"6

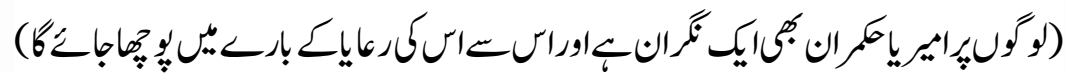

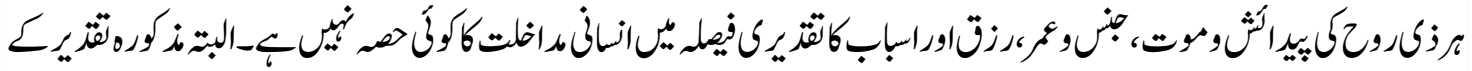

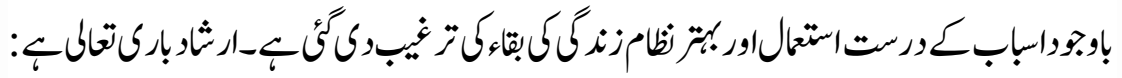

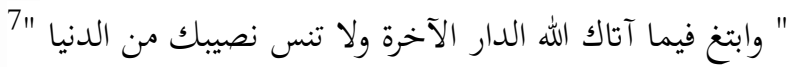

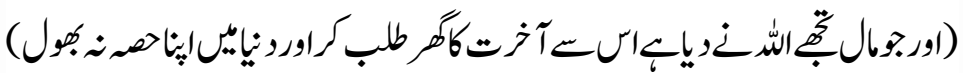

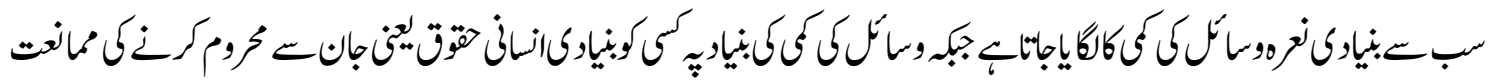

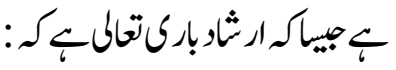

" ولا تقتلوا أولادكم من إملاق"

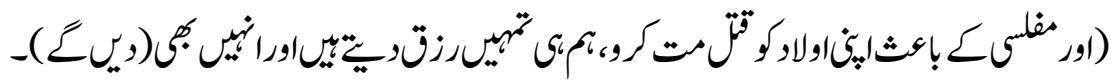

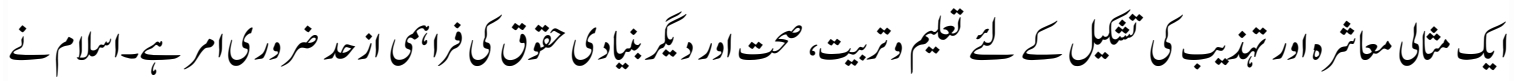

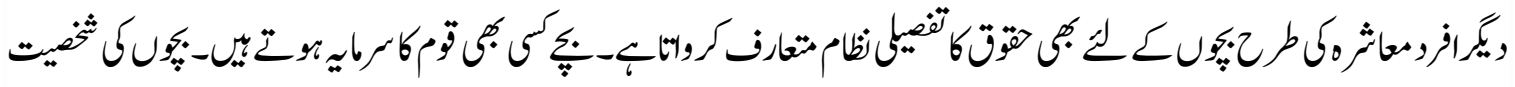

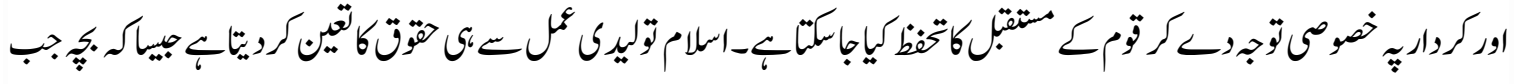

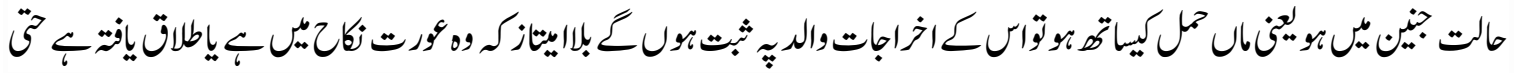

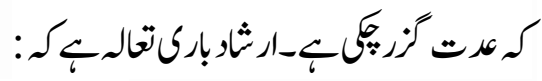

"وإن كن أولات حمل فأنفقوا عليهن حتى يضعن حملهن"

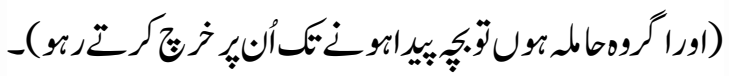

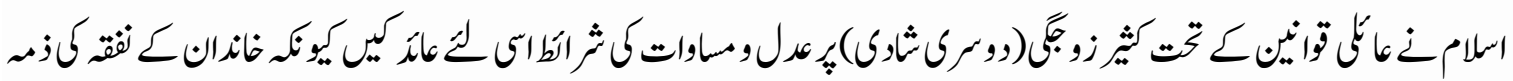

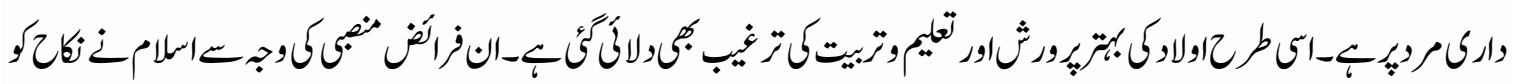

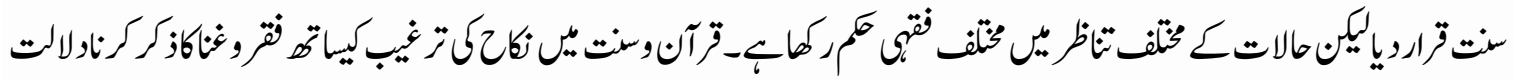

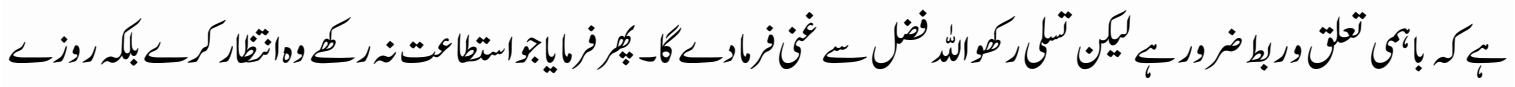

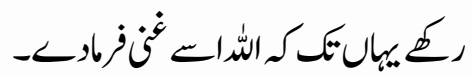

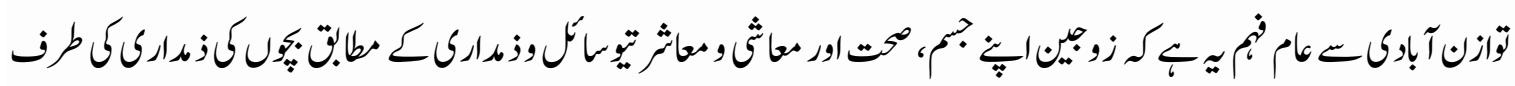

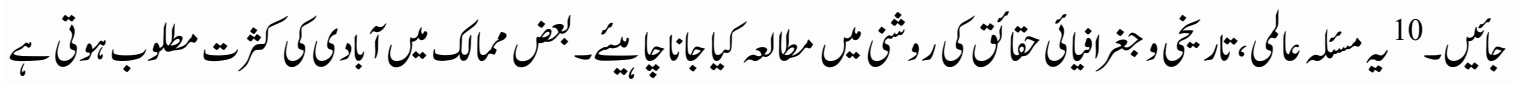




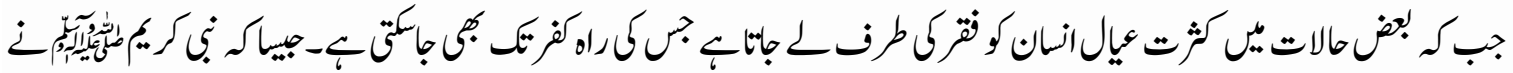

كاد الفقر أن يكون كفرًا" 11

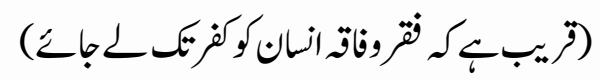

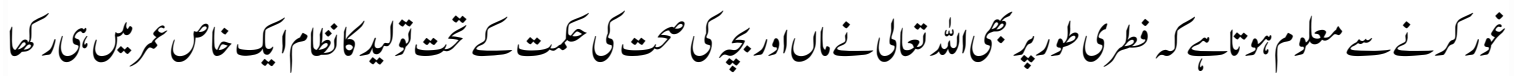

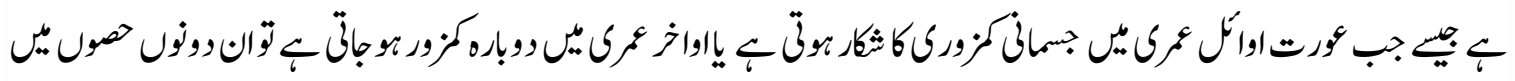

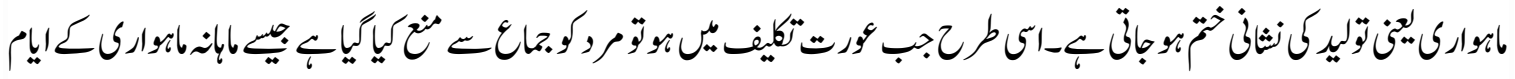

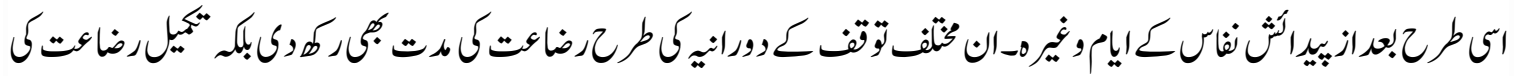

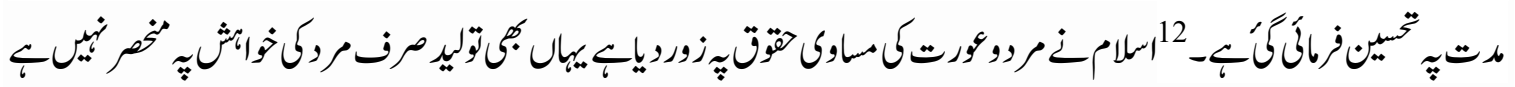

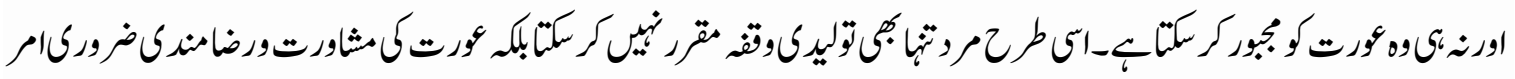

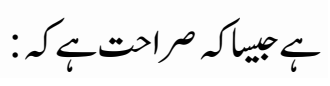
"13،عزل عن الحرة باذها،"

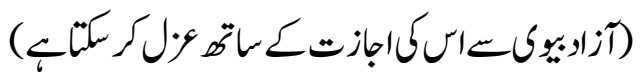

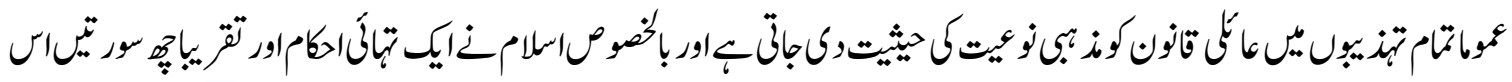

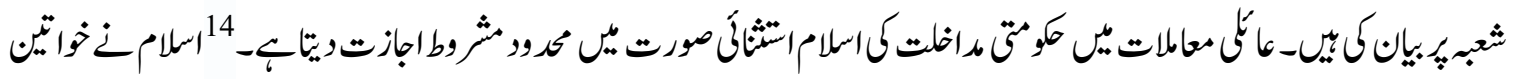

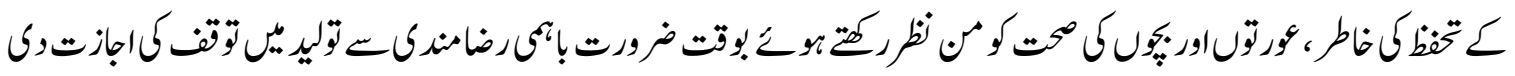

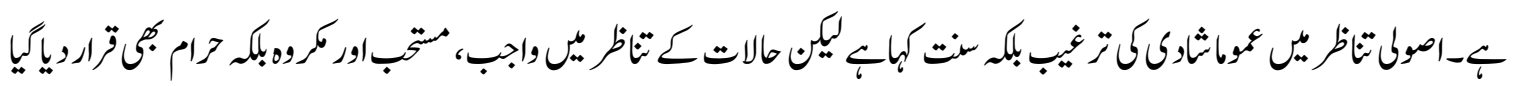

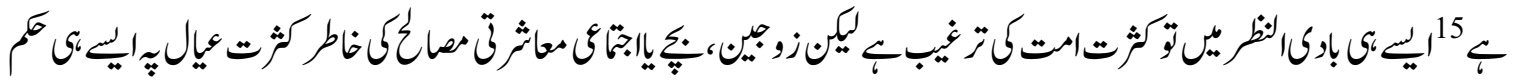

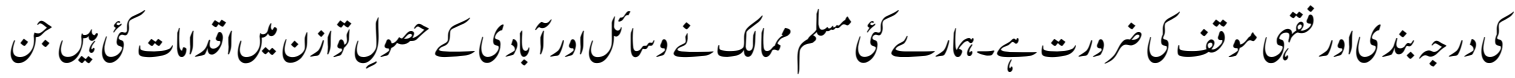

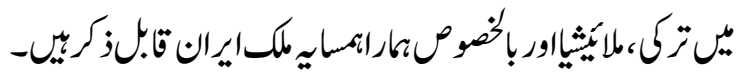

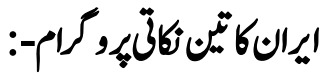
1 2 3 


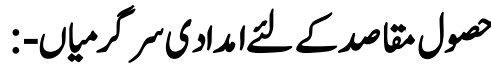

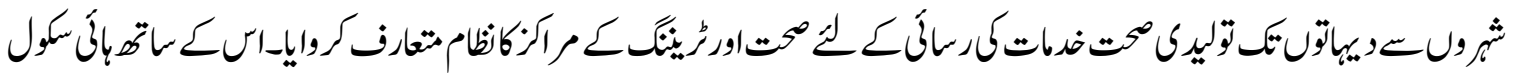

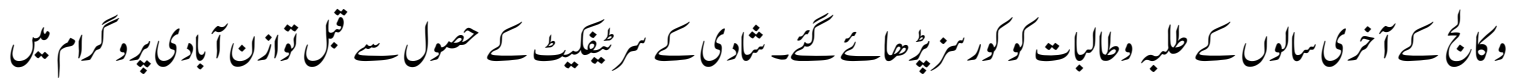

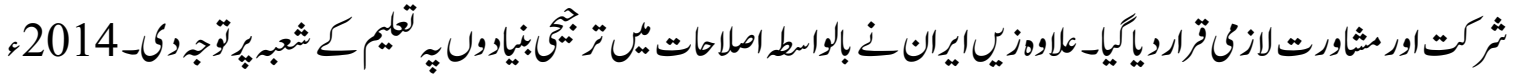

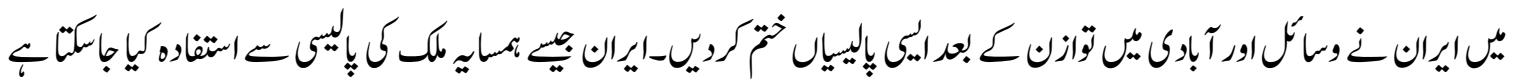

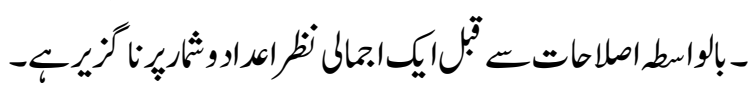

اعداوثثر:-

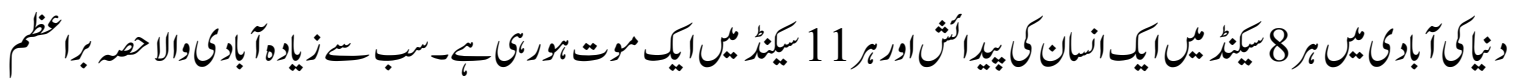

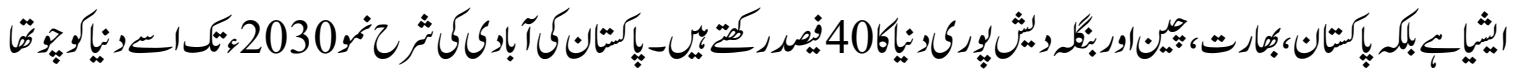

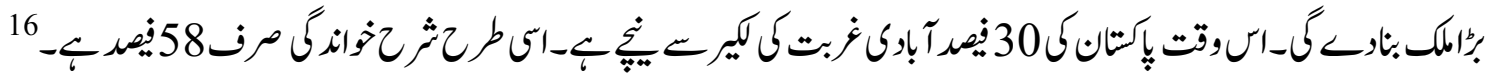

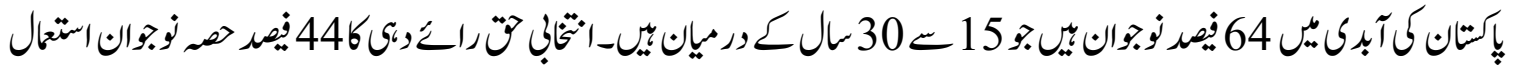

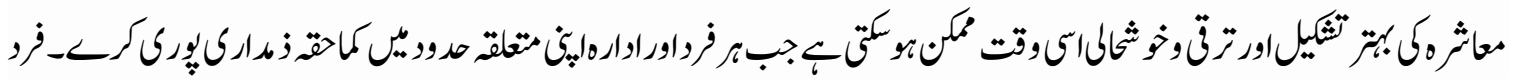

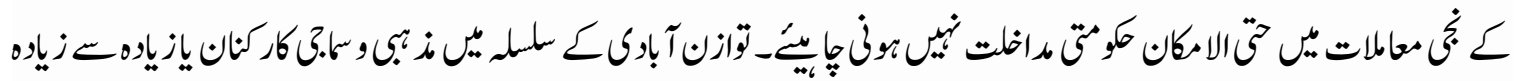

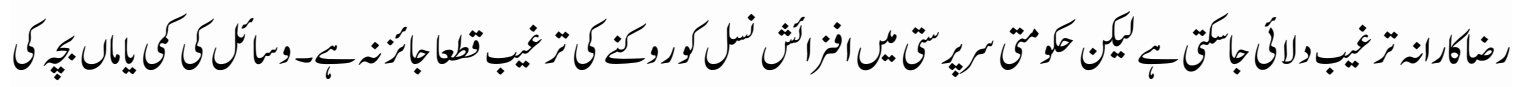

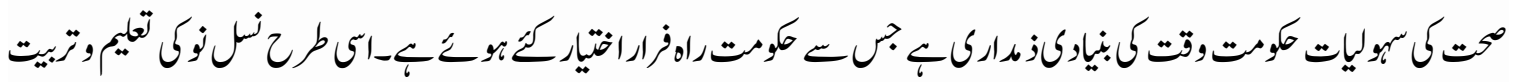

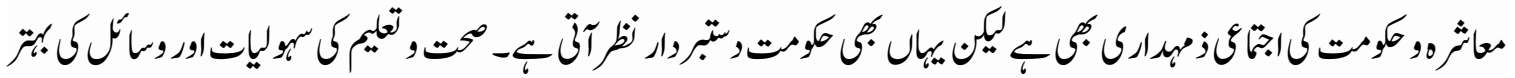

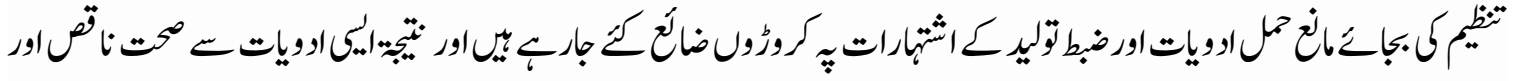

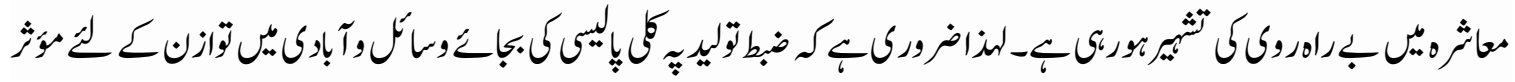

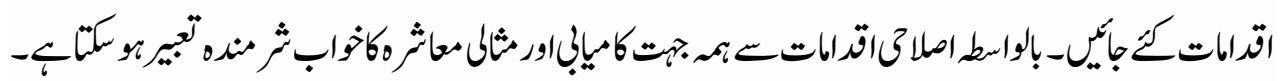

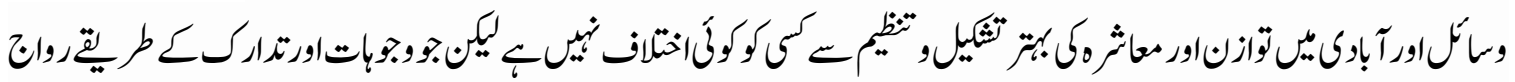

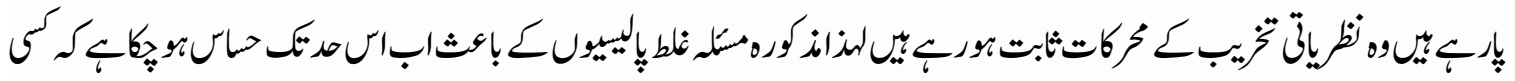

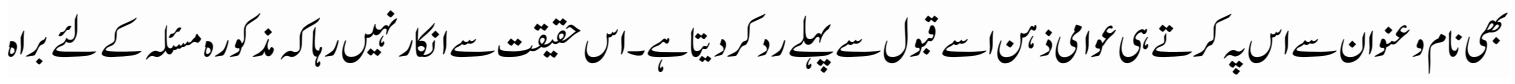




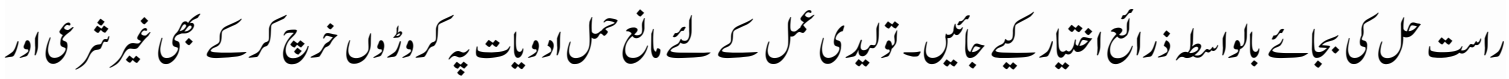

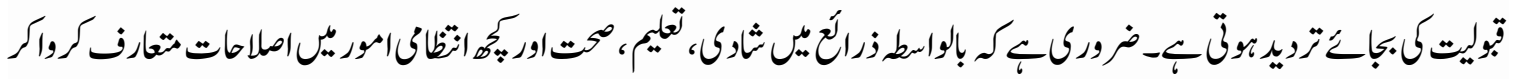

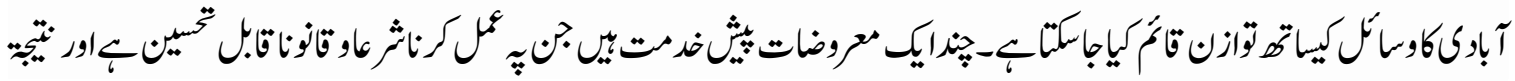

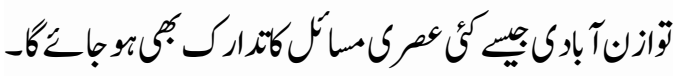

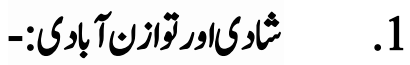

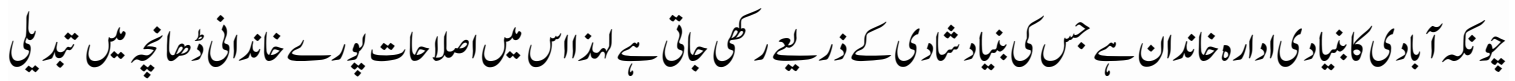

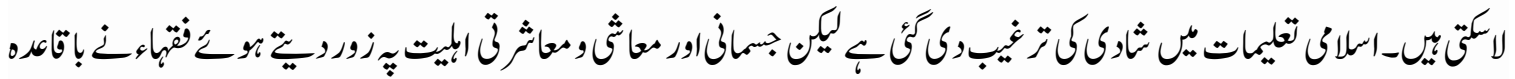

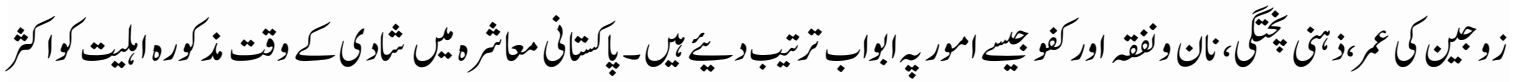

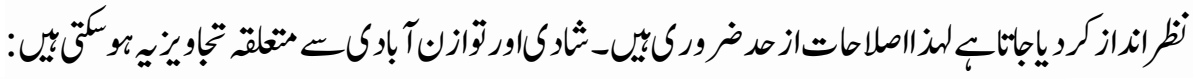

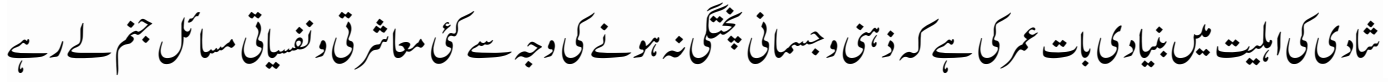

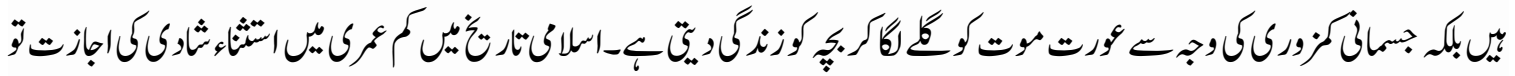

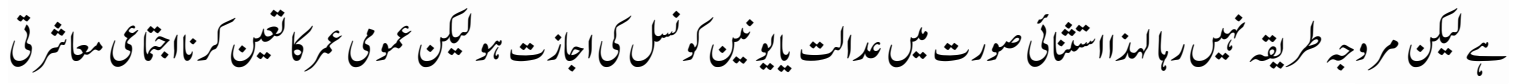

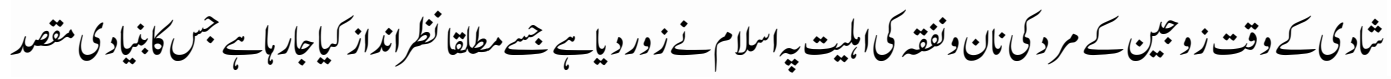

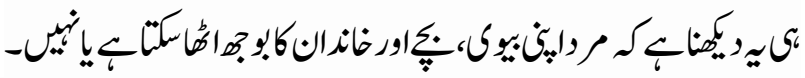

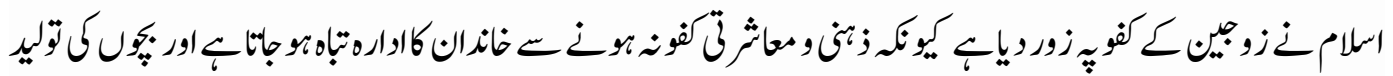

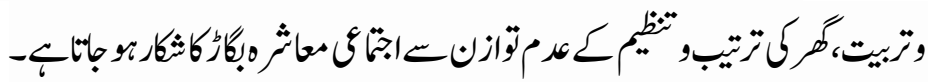

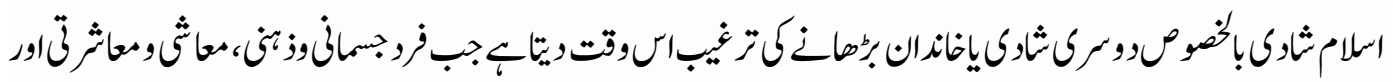

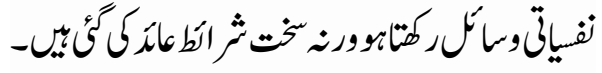

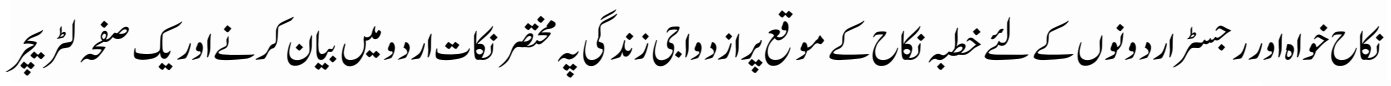
تقنيمكزمبرواركنو-

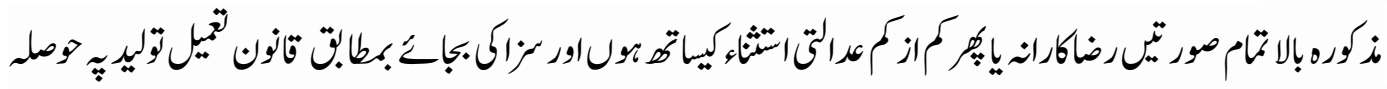
(6

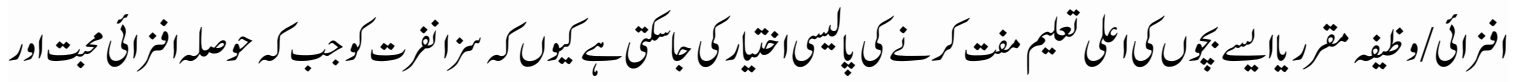

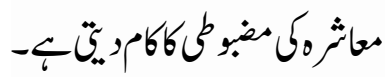




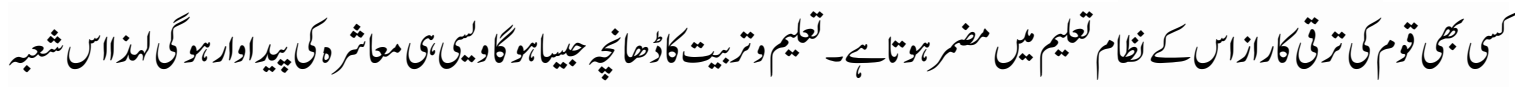

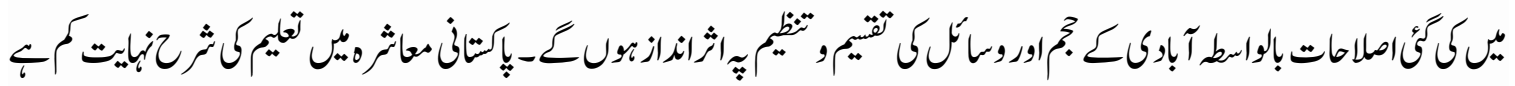

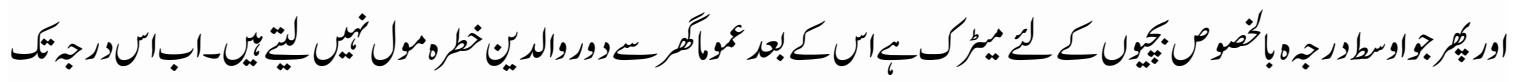

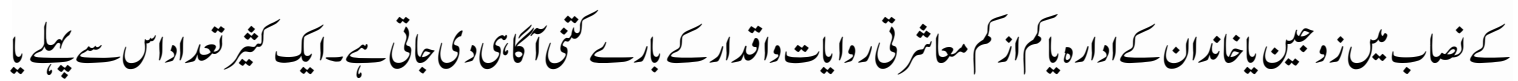

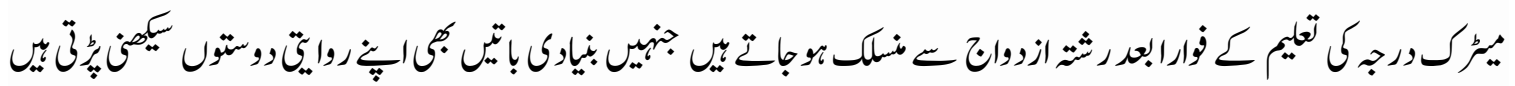

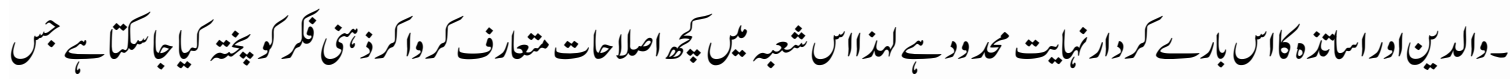

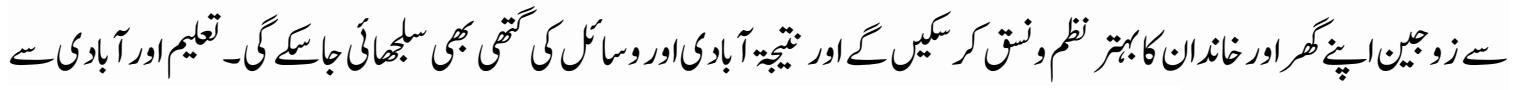

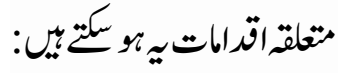

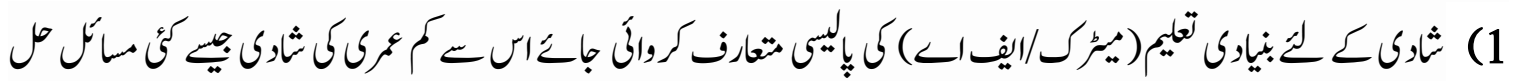

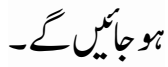

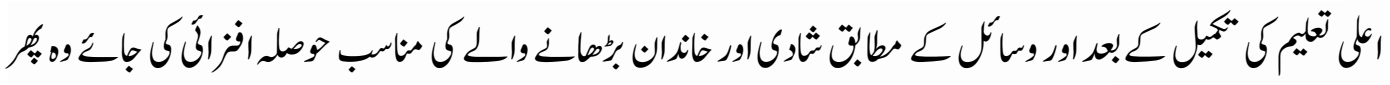

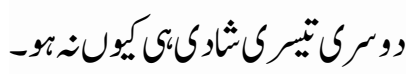

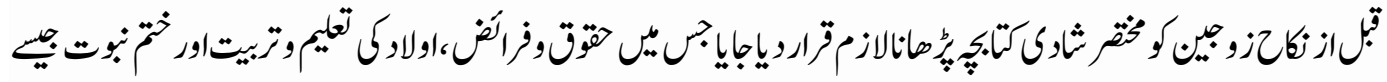

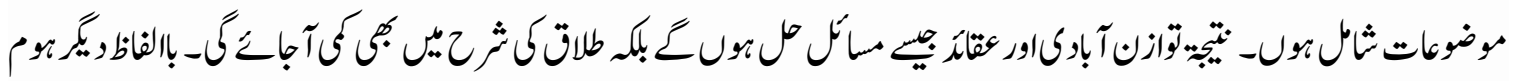

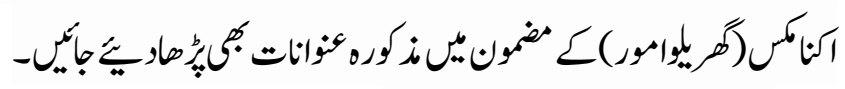

3. انتطاكاملاحات/ورتوازنآ آبرك:-

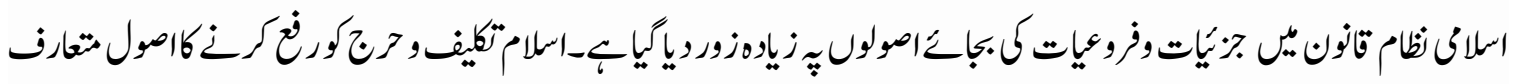

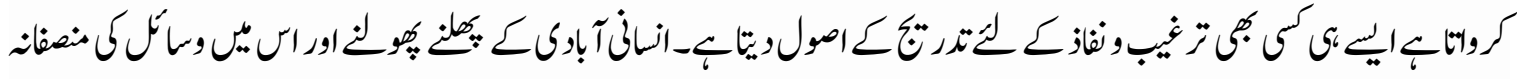

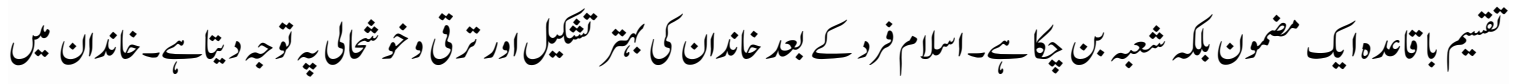

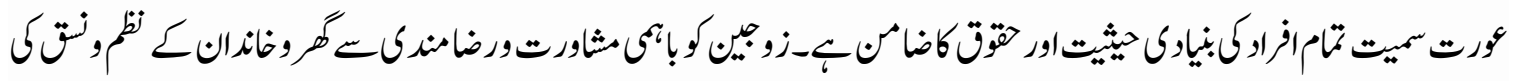

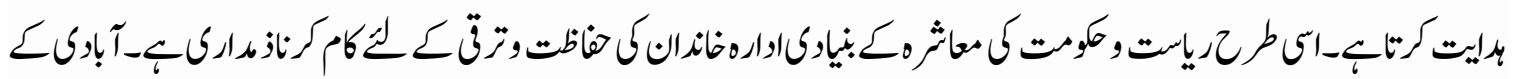

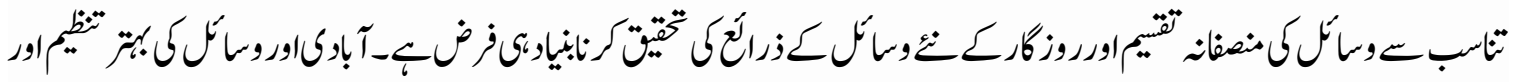

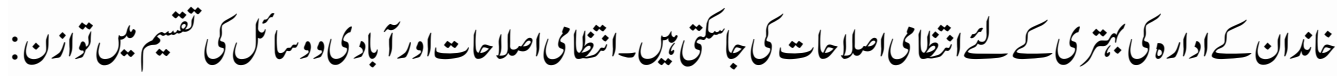




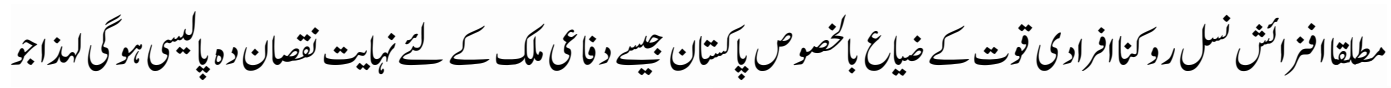

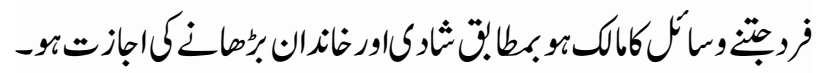

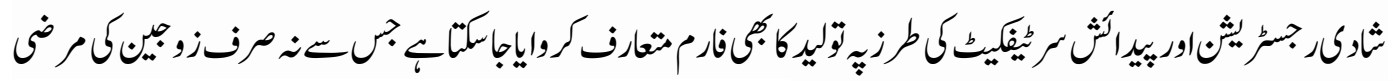

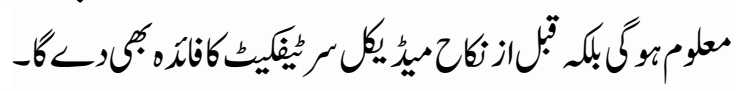

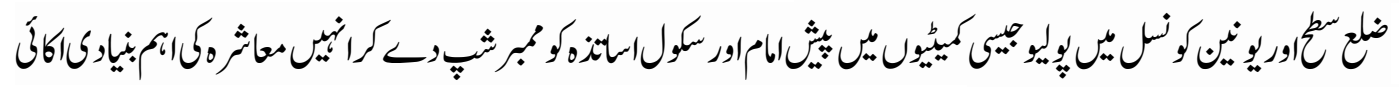

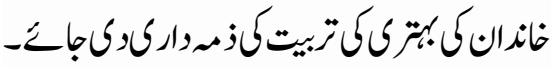

$$
\begin{aligned}
& \text { 4_اعراوثثاريإليىاورتوازن:- }
\end{aligned}
$$

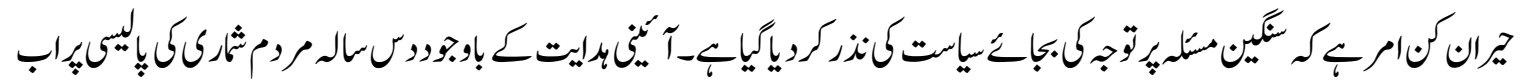

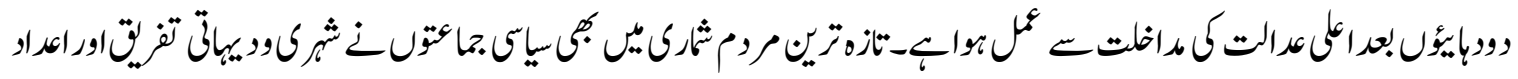

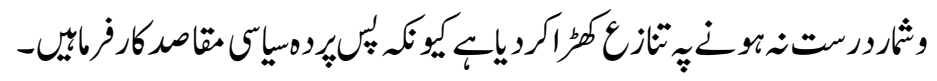

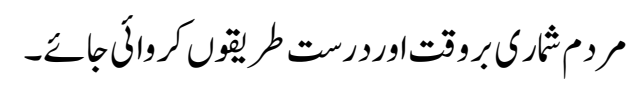

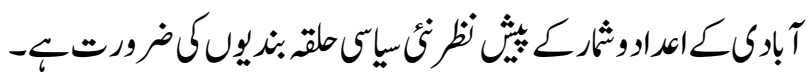

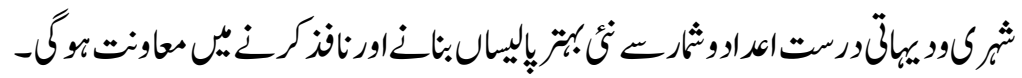

\section{5ـمحت|ور توازنا بارك:--}

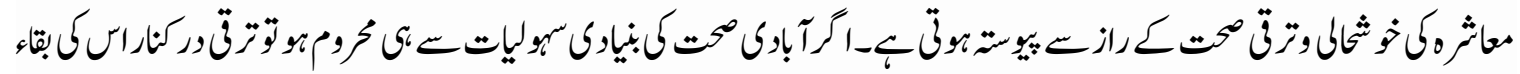

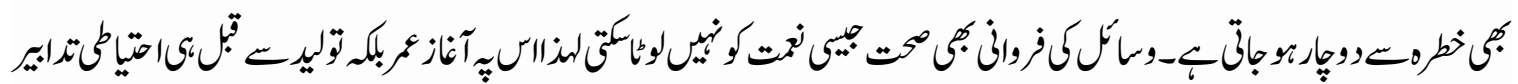

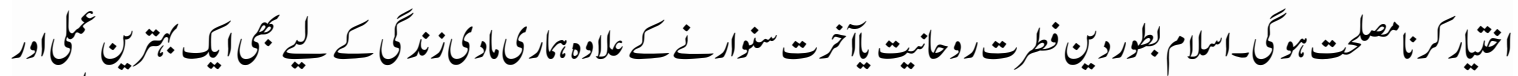

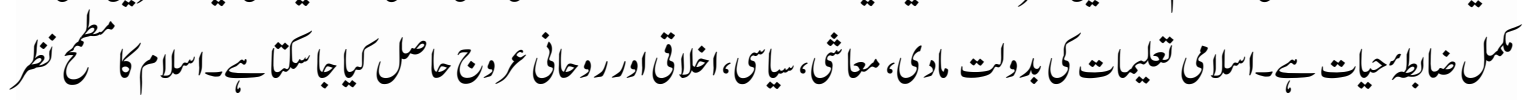

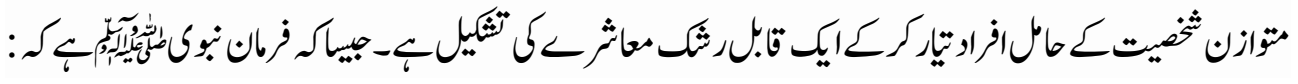

$$
\begin{aligned}
& \text { "لا تقتلوا أولادكم سرا فإن الغيل يدرك الفارس فيدعثره عن فرسه" }
\end{aligned}
$$

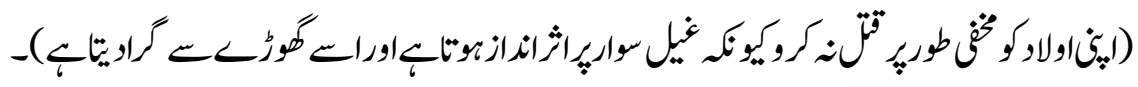

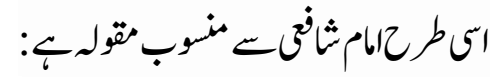

$$
\begin{aligned}
& \text { " العلم علمان، علم الأبدان، وعلم الأديان "19 }
\end{aligned}
$$

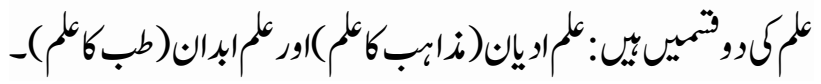




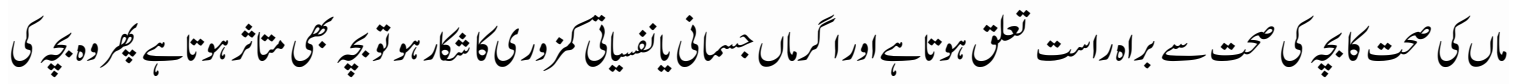

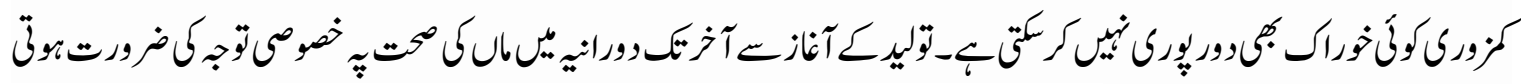

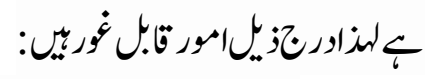

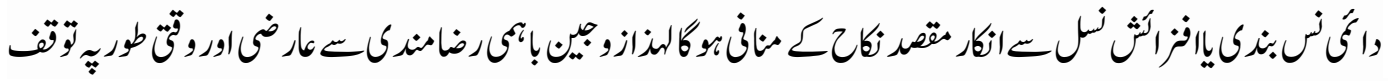

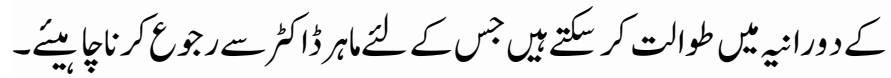

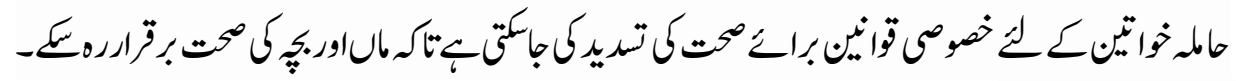

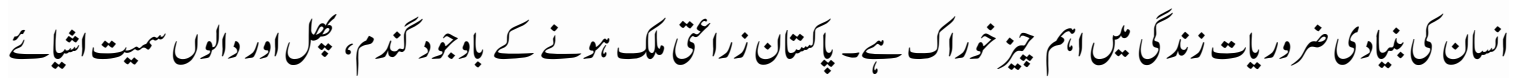

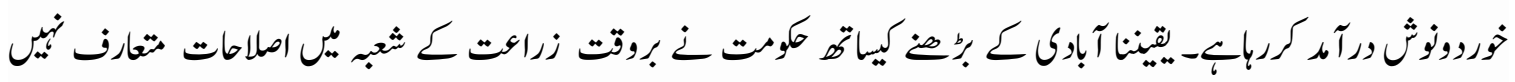

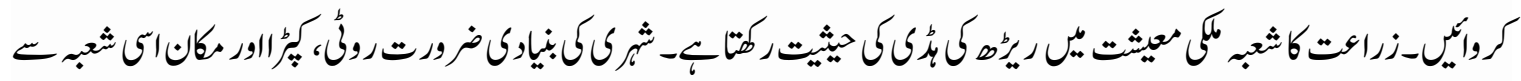

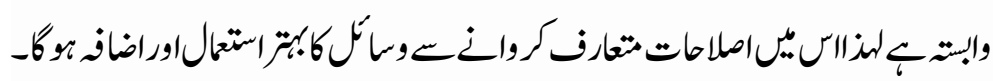

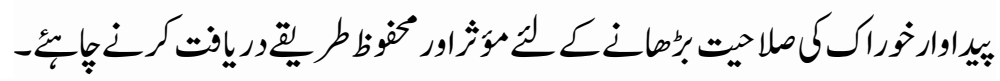

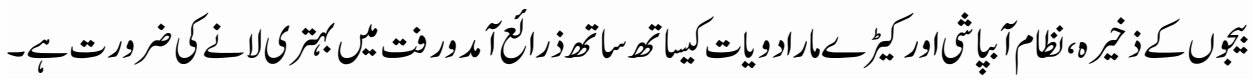

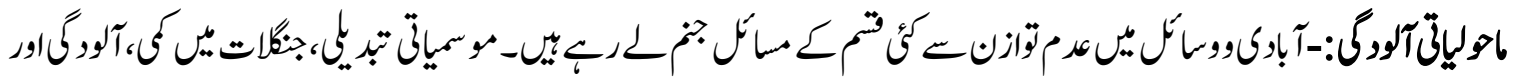

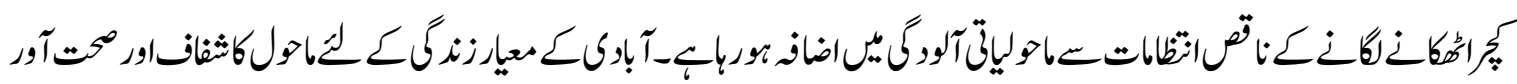

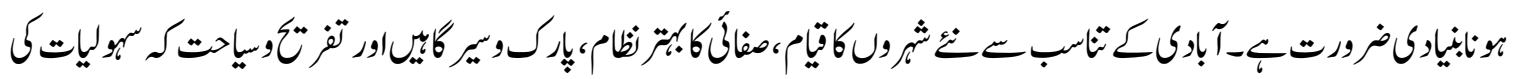

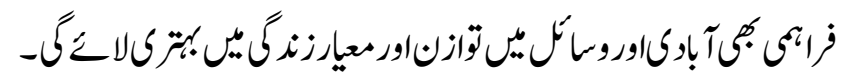

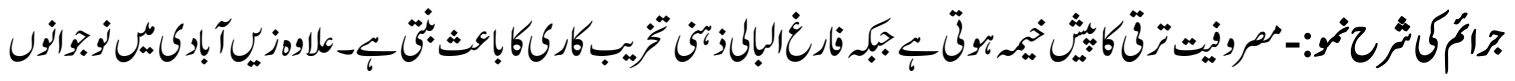

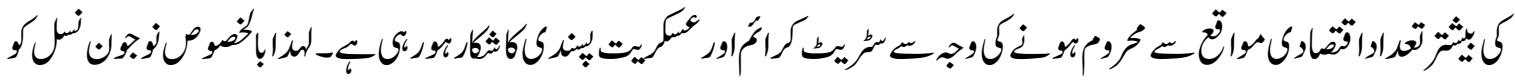

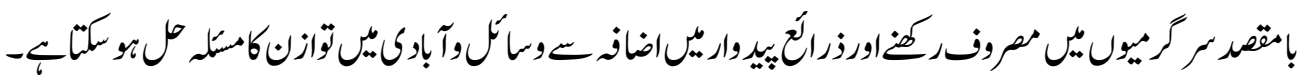

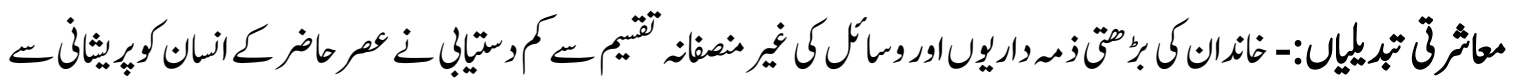

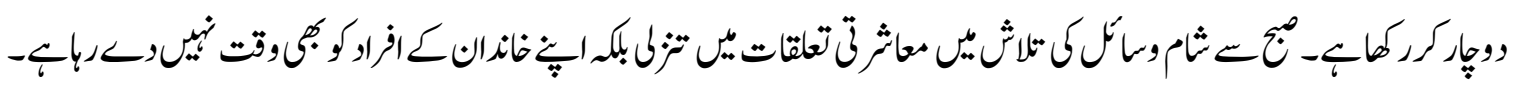

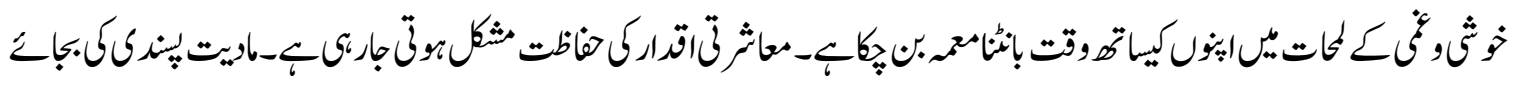




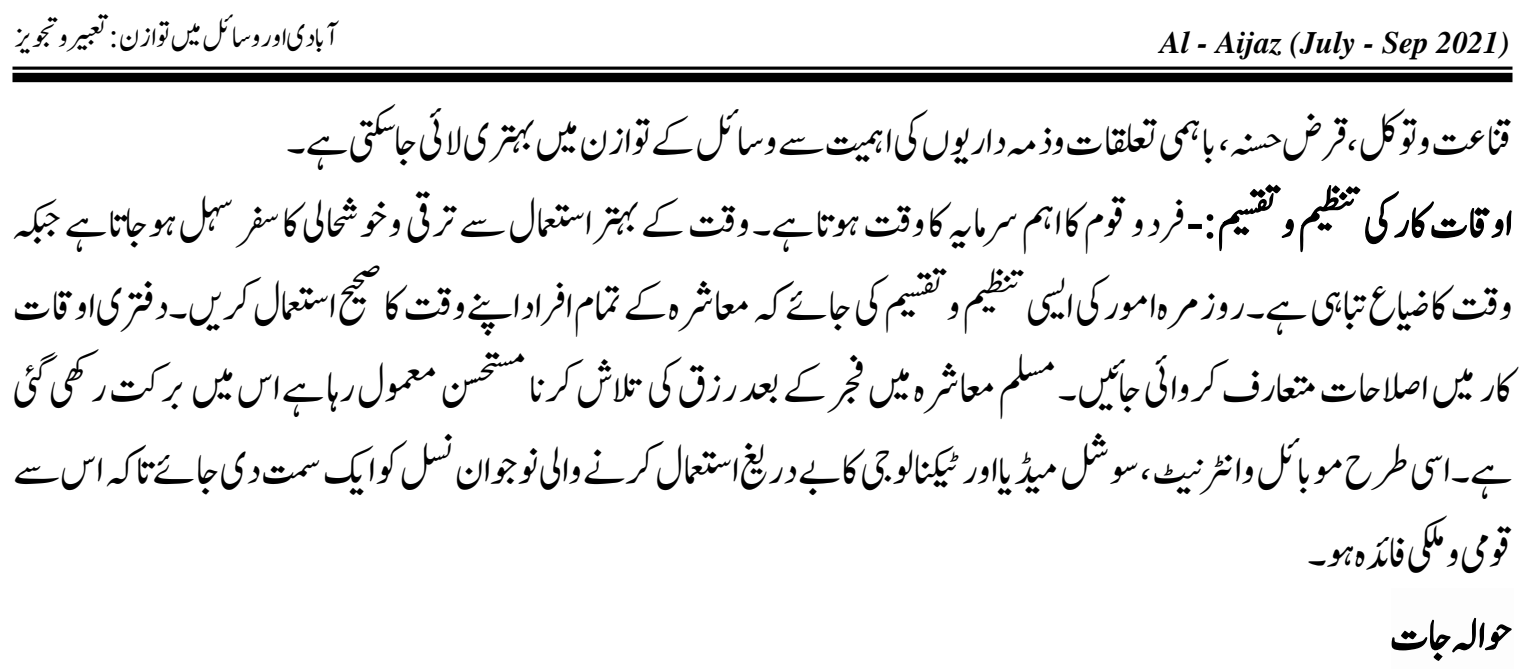

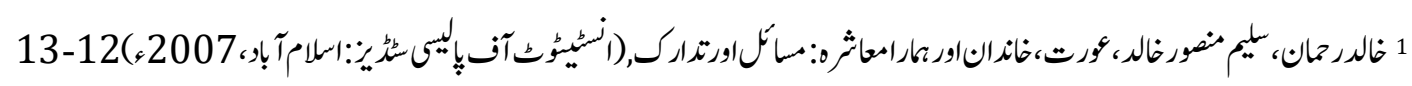
Khalid Rahman, Saleem Mansoor Khalid, Woman, Family and Our Society: Problems and Solution, (Institute of Policy Studies: Islamabad, 2007), 12-13

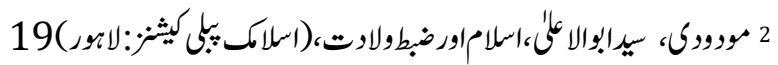
Maududi, Syed Abū al-A'lā Mawdūdī, Islam and Birth Control,(Islamic publications: Lahore)19

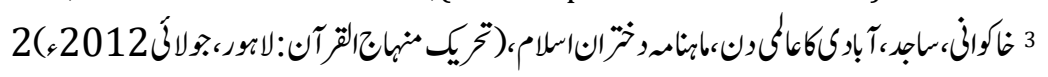

Khawkwani, Sajid, World day for Population, Monthly Dukhtran-e-Islam, ( Tahreek-e-Minhaj-ulQuran: Lahore, July 2012)2

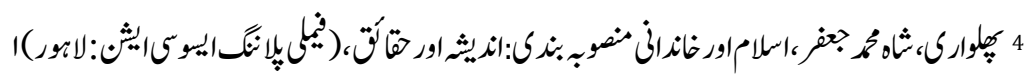

Phulwarvi, Jafar Shah, Islam and Family Planning: Fear and Facts, (Family Planning Association: Lahore) 1

Quran, 6:11

6:111 200

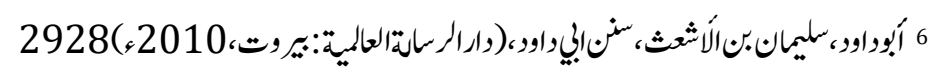

Abū Dā'ūd, Sulaymān ibn al-Ash'ath, Sunan Abi Dawood, (ar al-Risalah al-Alamiyah: Beruit, 2010) 2928

77:28 7

Quran, 28:77

151:6 8

Ibid. 6:151

65:6 9

Ibid. $6: 65$

10 Sheikh Niaz Ahmed, Urdu Encyclopedia of Islam, ( Idara Ma'arif Islami: Lahore, 1987) 447

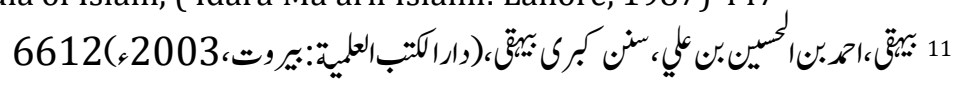


Bayhaqi, Ahmad ibn al-Husayn ibn `Ali, Sunan Kubra Bayhaqi,( Dar Al Kotob Al-Ilmiyah: Beruit,2003)6612

Quran, 2:233

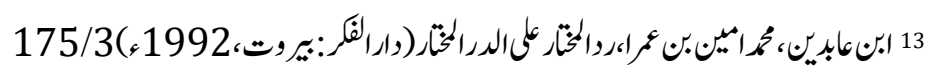

Ibn 'Abidin , Muhammad Amīn b. 'Umar b. 'Abd al-'Azīz, Radd al-Muhtār 'ala al-Durr al-Mukhtār,(Darul-Fikr: Beirut, 1992), 3/175

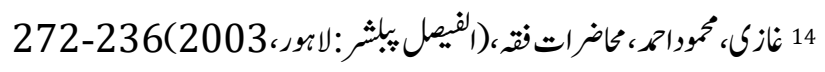

Ghazi, Mahmood Ahmed, Muhazrat e Fiqh, (Al Faisal Publishers: Lahore, 2003) 272-236

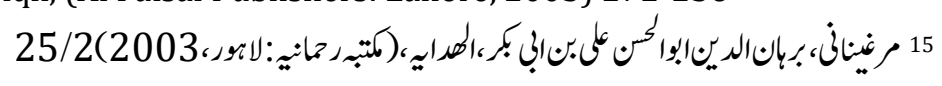

Marghīnānī‘ Burhān al-Dīn Abu'l-Ḥasan 'Alī bin Abī Bakr, Al-Hidayah, (Maktaba Rahmaniya: Lahore, 2003) $2 / 25$

16 Pakistan Demographic and Health Survey 2017-18 (National Institute of Population Studies: Islamabad)381

${ }^{17}$ https://kamyabjawan.gov.pk/home/urdusapmmessages

Bayhaqi, Sunan Kubra Bayhaqi, 7/464

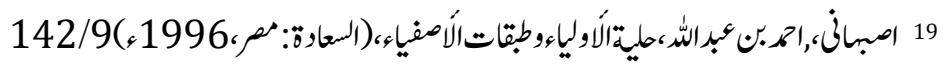

Asbhani, Ahmad bin Abdullah, Hilyat ul- Awliya wa Tabaqat-ul-Asfiya, (Al-Sa'adat : Egypt, 1996) 9/142 